Décadrages Décadrages

cınéma, à travers champs Cinéma, à travers champs

$7 \mid 2006$

Stephen Dwoskin

\title{
Jeune homme (Christophe Schaub, 2005)
}

\section{Alain Boillat}

\section{(Q) OpenEdition \\ Journals}

Édition électronique

URL : http://journals.openedition.org/decadrages/501

DOI : $10.4000 /$ decadrages. 501

ISSN : 2297-5977

\section{Éditeur}

Association Décadrages

\section{Édition imprimée}

Date de publication : 10 avril 2006

Pagination : 125

ISBN : 978-29700582-3-6

ISSN : 2235-7823

\section{Référence électronique}

Alain Boillat, " Jeune homme (Christophe Schaub, 2005) », Décadrages [En ligne], 7| 2006, mis en ligne le 31 janvier 2014, consulté le 19 avril 2019. URL : http://journals.openedition.org/decadrages/501 ; DOI : 10.4000/decadrages.501

Ce document a été généré automatiquement le 19 avril 2019

(B) Décadrages 


\title{
Jeune homme (Christophe Schaub, 2005)
}

\author{
Alain Boillat
}

Le dernier film de Schaub entre parfaitement dans le moule du film populaire censé «fédérer» les spectateurs helvétiques. L'histoire de ce Suisse-allemand qui décide de travailler au pair dans une famille genevoise thématise la traversée du Röstigraben et use à la fois d'un comique qui se veut universel. Toutefois l'humour parfois grivois y est dépourvu de finesse, et la réalisation d'une platitude totale. Face à un tel degré zéro de travail sur les pratiques filmiques - alors que la représentation spatiale de l'intérieur de la villa ou du voisinage aurait par exemple pu donner lieu à un traitement intéressant -, on ne peut qu'espérer que cette comédie non pas désagréable mais insipide donne au cinéaste les moyens de proposer (à nouveau) un cinéma plus exigeant. 